\title{
Research of Facts Devices for Stability
}

\author{
C. Sharan, S. Subasangkari, V.N. Ganesh, J. Ajay \\ Daniel
}

\begin{abstract}
Nowadays the consumption and need for the power is more hence there is great demand on power consumption by the people which may often cause instability in power system. This instability in Voltage or current in the power system can be controlled using various kinds of facts device. Hence, this paper explains the role of the facts devices in maintenance of stability and their optimal placements in power system. Thus this paper gives a comprehensive and comparative study of different types of facts device and their role in Voltage or transients stability analysis methods.
\end{abstract}

Keywords--- FACTS, Stability Analysis, Optimal Placements.

\section{INTRODUCTION}

The ability of the equipment to consume the energy being supplied to it is known as power quality. If the voltage stays within the prescribed range then it is said to be a good power quality or if it exceeds the prescribed range of voltage then it is said to be of poor quality.

There are many different ways for the power quality improvement[16].

The power system becomes unstable due to increase in power demand hence it becomes more difficult to operate and causes damage to the power system due to increase loss in power[1].

Nowadays a new technique known as facts device is used for the power quality improvement in power system. Optimization is a technique which is used to optimally locate the FACTS device in the power system[13].

Flexible alternating current transmission system (FACTS) is static equipment used for the $\mathrm{AC}$ transmission of electrical energy.

It is used for the enhancement of controllability and increases poor transfer capability[37]. It is generally a power electronic device.

There are many different types of FACTS devices are[15]:

Revised Version Manuscript Received on August 19, 2019.

C. Sharan, Student, Department of Electrical and Electronics Engineering, SRM Institute of Science and Technology. (e-mail: Sharan.chidam67@gmail.com)

S. Subasangkari, Student, Department of Electrical and Electronics Engineering, SRM Institute of Science and Technology. (e-mail: ssubasangkari@gmail.com)

V.N. Ganesh, Assistant Professor, Department of Electrical and Electronics Engineering, SRM Institute of Science and Technology. (email: vnganesh15@gmail.com)

J. Ajay Daniel, Assistant Professor, Department of Electrical and Electronics Engineering, SRM Institute of Science and Technology. (email: ajaydaniel23@gmail.com)

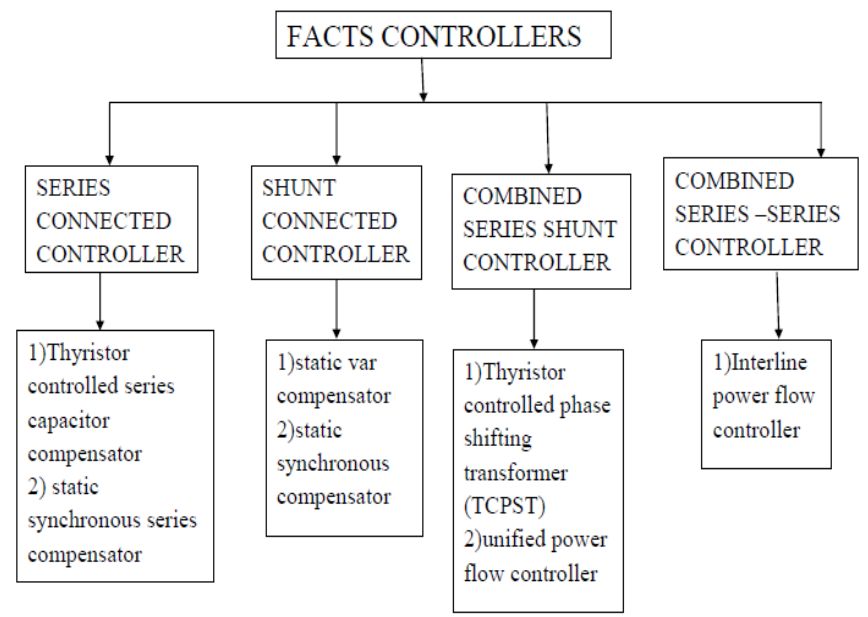

Figure 1: Classification of FACTS devices

Out of these facts devices we choose,

- STATCOM

- IPFC

- TCSC

For the review purpose as they are more important than the others.

The optimal placement of facts devices explains us about, where these facts devices has to be placed and their correct location in the power system[2,9]. Such as STATCOM is usually placed in the midpoint of the transmission lines and TCSC is placed at the $500 \mathrm{KV}$ transmission lines and IFPC acts as a voltage source converter[3,10].

Power system all over the world has to be operated very close to stability limits owing to the ever increasing power demand[5].

If the system returns back to its normal form then it is said to be a stable system otherwise the system is said to be unstable[25,40]. This maintenance of stability in the power system can be achieved by some useful techniques using FACTS devices.

\section{STATIC SYNCHRONOUS COMPENSATOR (STATCOM)}

A static synchronous compensator (STATCOM) is a directing device utilized on alternating current transmission systems[7]. It depends on power devices such as voltagesource converter and can act as either a source or sink of reactive AC capacity to an electric network. If it is associated with the power source it can also provide active $\mathrm{AC}$ power. 
It is an individual from the FACTS group of device[31]. It is intrinsically secluded and electable.

These compensators are likewise usable to lessen voltage changes. The STATCOM is used to support the electrical network that has poor power factor and poor voltage regulation[8,12]. A STATCOM is a voltage source converter (VSC) - based device, with the voltage source behind a reactor.

The voltage source is made from a DC capacitor and along these lines a STATCOM has less reactive power ability[18]. In any case, its active power ability can be enhanced if an appropriate energy storing device is associated over the DC capacitor. The reactive power at the terminals of the STATCOM relies upon the amplitude of the voltage source[28].

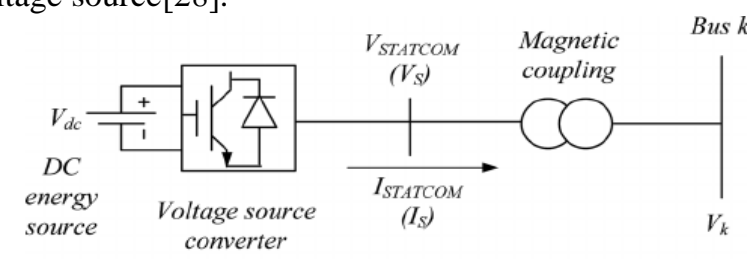

(a)

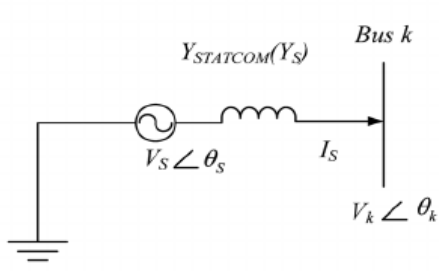

(b)

Figure 2: Equivalent circuit of the STATCOM

The optimal placement of the STATCOM in the buses is found here dependent on the voltage sensitivity[14]. As of now, sensitivity investigation is ending up to an ever increasing extent essential in practical power system activities[21].

The power administrator utilizes these to study and monitors the power system and identifies the defects in the power system[19]. Voltage imbalance is basically connected with reactive power instability in a nearby organize or a predefined transport in a system which isknown as the frail transport[26,39]. In this manner voltage sensitivity factor is utilized by selecting the ideal areas of VAR support.

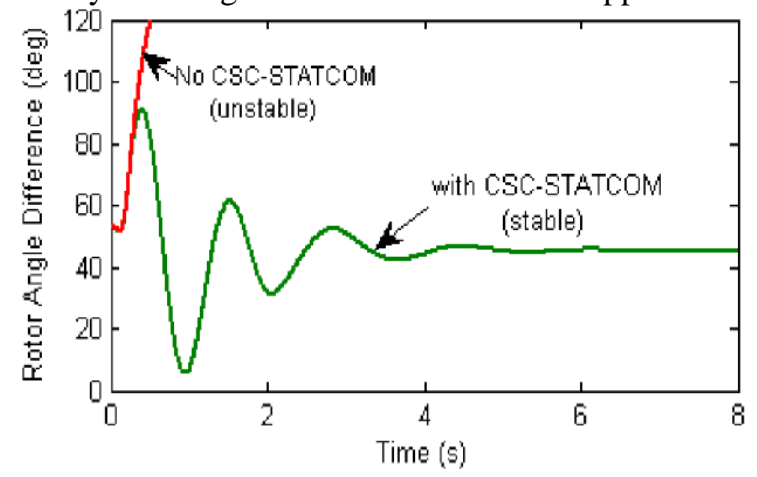

Figure 3: Stability analysis waveform with or without STATCOM

The system is bought back to control by injecting the current in parallel to the line that changes the reactive power which in turn influences the rotor angle. Thus the best optimal placement of the STATCOM can be obtained[41].

The STATCOM plays out indistinguishable capacity from the SVC. This is because of the way that the most extreme capacitive power produced by a SVC is corresponding to the square of the system voltage (consistent susceptance) while the greatest capacitive power created by a STATCOM diminishes straightly with voltage (steady current) $[43,44]$. This capacity to give progressively capacitive responsive power amid blame is one imperative preferred standpoint of the STATCOM over the SVC[50,51].The STATCOM can be worked in two unique modes: In voltage guideline mode (the voltage is managed inside breaking points as clarified beneath)[23]. In var control mode (the STATCOM receptive power yield is kept consistent).

\section{INTERLINE POWER FLOW CONTROLLER (IPFC)}

Interline Power Flow Controller. The goal of acquainting this controller is with location the issue of repaying various transmission lines associated at a substation[17].

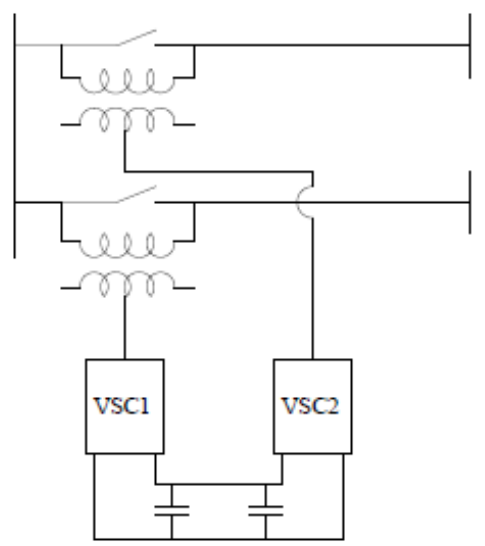

Figure 4: Equivalent circuit of IPSC

The dynamic power stream in a line is controlled or directed by the series reactive compensation (as a TCSC or $\mathrm{SSSC}$ [22]; the control of reactive power isn't possible except if dynamic (genuine) voltage in stage with the line current isn't infused[29].

The use of a TCSC (or SSSC with impedance copying) results in the decrease of net arrangement reactance of the line. In any case, $X / R$ proportion is decreased fundamentally and accordingly expands the responsive power stream (infused at the less than desirable end) and losses in the line[24]. All the dc capacitors of individual converters are connected in paralleled such that they provide controllable series compensation to each and individual line by transferring the real power series connected VSCs with the lines[58].

This is achievable as all the series converters are located closest to the substation. The UPFC is more similar to that of the IPFC in magnitude and phase angle of the given voltage in the primary system that can be controlled by transferring the real power with the secondary system[35,36].

The essential distinction with an UPFC is that the emotionally supportive network in the last case is the shunt converter rather than an arrangement converter[32].

Published By:

Blue Eyes Intelligence Engineering

\& Sciences Publication 
The arrangement converter related with the primary system (of one IPFC) is named as the monitor converter while the arrangement converter related with the secondary network is named as the slave converter[20].

The monitor converter controls both the dynamic and reactive voltage within a considerable range while the slave converter controls the DC voltage (over the capacitor) and the reactive voltage extent[30].Correlation of results with different areas guarantees that arrangement of IPFC at the proposed area is a sound area for the arrangement of IPFC regarding decrease of blockage. A decrease in Genuine and receptive power misfortune has likewise been watched[34]. Thus, the general system execution has been concentrated under various stacking conditions and the outcomes are observed to be good.

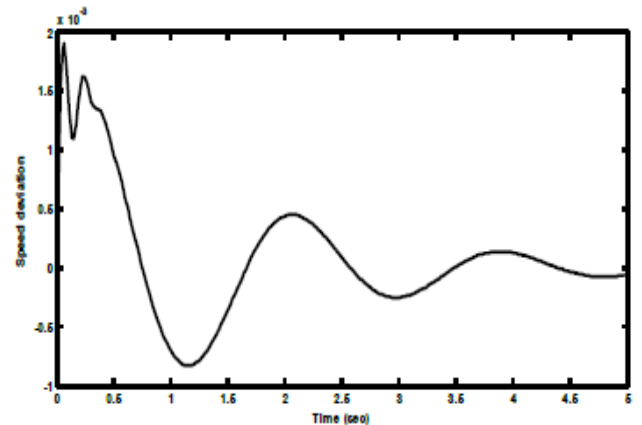

Figure 5: Angle deviation waveform without IPFC

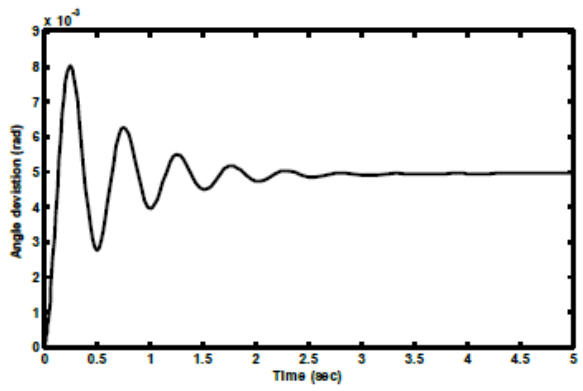

Figure 6: Angle deviation waveform with IPSC

\section{THYRISTOR CONTROLLED SERIES COMPENSATION (TCSC)}

The reactance of transmission line is compensated to control the power flow by using the TCSC which is one of the series compensator[6]. It is located either at the center of transmission lines or at the line terminals but in most of the cases it is located at the center of the transmission line[11]. This is because the fault current in the center of the transmission line are low.

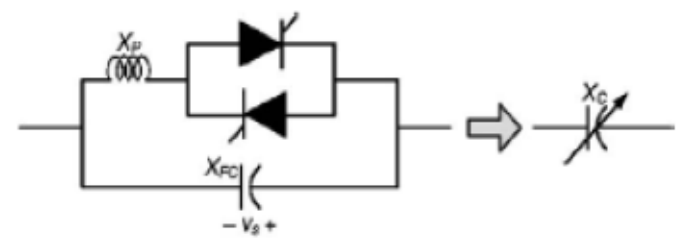

Figure 7: Equivalent circuit of TCSC

The TCSC present in transmission lines is useful for maintenance of power system.

Voltage collision:

While comparing STATCOM and IPFC the voltage collision in transmission lines is more when we use TCSC. With TCSC:
Without TCSC:

$$
V=E \cos (\delta) \pm \sqrt{ } E^{2} \cos ^{2}-4 Q_{L} x / 2
$$

$V=E \cos (\delta) \pm \sqrt{E^{2} \cos ^{2}(\delta)-4 Q_{L}\left(x-x_{1} \csc (a)\right) / 2}$

$\delta$ - Rotor angle of generator

$\mathrm{Q}_{\mathrm{L}}$ - load reactive power

The SMDL system is unstable with positive and real Eigen values of TCSC. Since the stability level is less using TCSC LQR controller is added to the system. LQR controller when added to the system it provides more stability to the overall system[55,56].

The smooth variable series capacitive reactance is provided by the thyristor controlled reactor when shunted by the series capacitor bank that consists of capacitive reactance compensator[57].The series impedance is changed it increase the loadability of the power system and reduces the transmission losses when the thyristor controlled series capacitors are installed in the transmission lines[45,46].

This model limits the normal estimation of intensity misfortune cost and the venture cost of TCSC thinking about the likelihood of various situations, which are created by utilizing the traditional copula hypothesis, where the transient relationship among wind and burden is considered[53,54].

At that point the linearization strategies are embraced to change the model to a blend whole number straight program. Thyristor Controlled Series Capacitors (TCSC) addresses explicit dynamical issues in transmission systems[48,49]. Right off the bat it increments damping when vast electrical system are interconnected. Also it can defeat the issue of Sub-Synchronous Resonance (SSR), a wonder that includes cooperation between expansive warm producing units and arrangement remunerated transmission system[59,60].

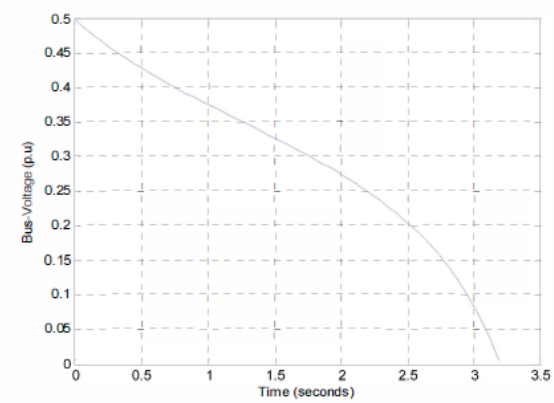

Figure 8: Voltage waveform without TCSC

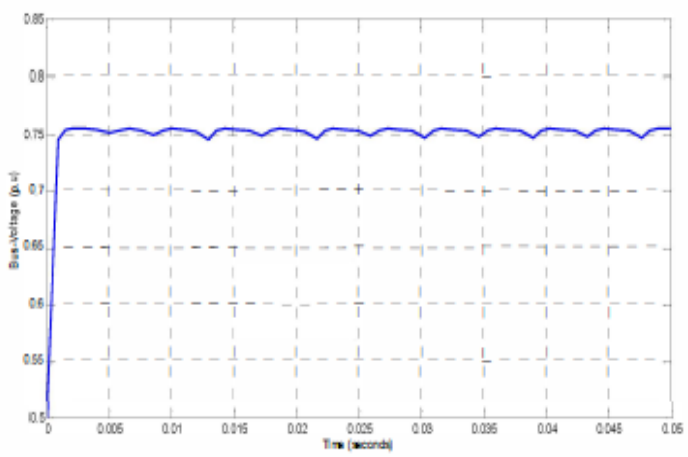

Figure 8: Voltage waveform with TCSC 


\section{COMPARISON BETWEEN THE STATCOM, IPFC, TCSC}

Table 1: Comparisons between STATCOM, IPSC and TCSC

\begin{tabular}{|c|c|c|}
\hline TOPICS & STATCOM & IPFC \\
\hline expansion & $\begin{array}{l}\text { Static synchronous } \\
\text { Compensator. }\end{array}$ & Inter \\
\hline Definition & $\begin{array}{l}\text { STATCOM is usually connected } \\
\text { in shunt and it is one of the } \\
\text { FACTS devices used in power } \\
\text { electronics and to improve the } \\
\text { instability on power grids. }\end{array}$ & $\begin{array}{l}\text { IPFC } \\
\text { in } \mathrm{m} \\
\text { and } \mathrm{i} \\
\text { conve }\end{array}$ \\
\hline $\begin{array}{l}\text { Optimal } \\
\text { placements }\end{array}$ & $\begin{array}{l}\text { It is placed at the midpoint of the } \\
\text { of the transmission lines. }\end{array}$ & $\begin{array}{l}\text { It is } \\
\text { lines }\end{array}$ \\
\hline $\begin{array}{l}\text { Technical } \\
\text { characteristics }\end{array}$ & $\begin{array}{l}\text { 1. Voltage control VAR } \\
\text { compensation. } \\
\text { 2. Transient and dynamic } \\
\text { Stability. } \\
\text { 3. Voltage stability } \\
\text { Damping oscillations }\end{array}$ & \\
\hline $\begin{array}{l}\text { Stability } \\
\text { analysis curve }\end{array}$ & - & \\
\hline
\end{tabular}

\section{CONCLUSION}

Thus this paper gives us a complete review on the three facts devices such as STATCOM, TCSC, and IPFC in a comparative manner. This paper also gives us their role in stability analysis. Thus STATCOM is used for the control of faults in the transmission system while TCSC is used for the control of voltage and IPFC is used to control the current and power instability. We find that IPFC is comparatively better than STATCOM and TCSC because it has better controllability on the power system fault.But cost wise STATCOM is the cheaper than IPSC.

\section{REFERENCES}

1. Manisha Rani, Anjugupta;"Steady state Voltage stability enhancement of the power system using FACTS devices" 2014.

2. NitishRawat,Ashutosh Bhatt, PankajAswal"A Review on Optimal location of FACTS devices in AC transmission system"2013.

3. BasanagoudaPatil,S B Karajgi;"A Review on Optimal Placement of FACTS Devices in Deregulated Environment- A Detailed Perspective"2017.

4. Smitkumar D. Choudante,A. A. Bhole;"A Review:Voltage Stability and Power Flow Improvement by using UPFC Controller" 2018.

5. F. E. Ciausiu, Member, IEEE, M. Eremia, Senior Member, IEEE;"Improvement of Power Systems Security Margins by Using FACTS devices"2011.

6. Ricardo J. Dávalos, Juan M. Ramírez;"A Review of a Quasi-Staticand a Dynamic TCSC Model"2016.

7. Dinesh Kumar, Ajay Kumar;"Stability Analysis of Multi-Machine System using STATCOM"2014.
TCSC

Thyristor controlled series compensation.

TCSC is utilized in power frameworks to progressively control the reactance of a transmission line so as to give adequate burden remuneration.

It is placed at the transmission lines of $500 \mathrm{kv}$.

1. Current control.

2. Transient and dynamic Stability.

3. Voltage stability damping oscillations.
1. Voltage Reactive control.

2. Transient dynamic Stability.

3. Voltage stability damping oscillations.
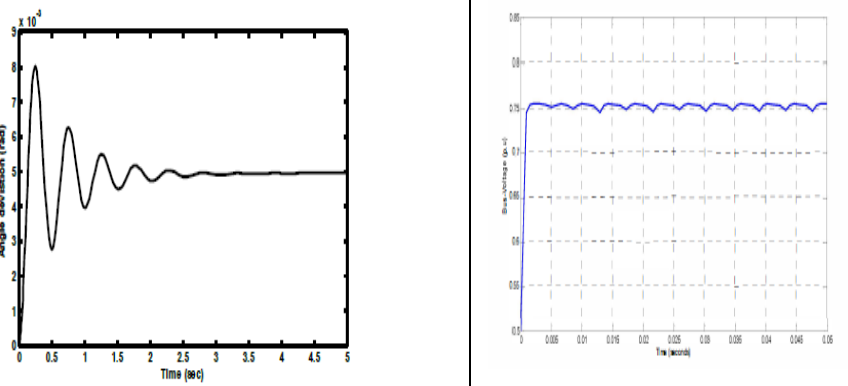

8. K.Karthikeyan, P.K.Dhal; "Optimal Location of STATCOM based Dynamic Stability Analysis tuning of PSS usingParticle Swarm Optimization"2016.

9. V.P.Rajderkar and V.K.Chandrakar,"Comparison of series FACTS Devices Via Optimal Location in a Power System forCongestion Management", APPEE Conference, 2009.

10. S. Gerbex, R. cherkaoui and A.J. Germond, "Optimal Location of FACTS devices to enhance power system security”, 2003.

11. G.Swapna, J.ShriniwasRao, J.Amarnath, "Sensitivity Approach to improve Transfer capability through optimal placement ofTCSC and SVC", International Journal of Advances in Engineering and Technology, July 2012.

12. Varshney S., Srivastava L., Pandit M., "Optimal placement and sizing of STATCOM for voltage security enhancement using PSO-TVAC," International Conference on Power and Energy Systems, pp.1-6, Dec. 2011.

13. Optimal placement of FACTS devices for voltage stability using line indicators Anju Gupta; P. R. Sharma 2012 IEEE FifthPower India Conference Year: 2012.

14. Michal Koltun; KaamranRaahemifar ,"Optimal placement and sizing of STATCOMs in power systems using GHS Algorithm", IEEE 30th Canadian Conference on Electrical and Computer Engineering (CCECE), 2017.

15. Hingorani, "FACTS Controllers in Transmission and Distribution Systems".

16. EsmaeilGhahremani; Innocent Kamwa“Optimal placement of multiple-type FACTS devices to maximize power systemloadability using a generic graphical user interface" IEEE Transactions on Power Systems, 2013 .

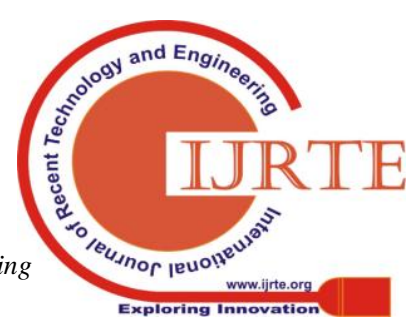


17. B. V. Rami Reddy; Y. V. Siva Reddy; P. Sujatha,"Optimal placement of interline power flow controller (IPFC) to enhance voltage stability" Conference on Power, Control,

18. Communication and Computational Technologies for Sustainable Growth (PCCCTSG),2015.

19. GarimaChoudhary; NirajSinghal; K. S. Sajan,“Optimal placement of STATCOM for improving voltage profile and reducing losses using crow search algorithm", International Conference on Control, Computing,Communication and Materials (ICCCCM).

20. J. Nikoukar, M. Jazaeri, "Genetic Algorithm Applied toOptimal Location of FACTS Devices in a PowerSystem" Proc. of the 3rd IASME/WSEAS Int. Conf. onEnergy, Environment, Ecosystems and SustainableDevelopment, AgiosNikolaos, Greece, 24-26 July,2007.

21. S.Gerbex, R. Cherkaoui, A. J. Germond, "Optimal Location of FACTS Devices to Enhance Power System Security", IEEE Bologna Power Tech Conference, Bologna, Italy, 23-26 June, 2003.

22. WeerakornOngsakul, PeerapolJirapong, "Optimal Allocation of FACTS Devices to Enhance Total Transfer Capability Using Evolutionary Programming", IEEE Transactions, 2005.

23. Dr . Ibrahim Oumarou, Prof. Daozhuo Jiang,Prof. Cao Yijia, "Optimal Placement of Shunt Connected Facts Device in a Series Compensated Long Transmission Line" Proceedings of the World Congress on Engineering 2009 Vol I, London, U.K, 1-3 July, 2009.

24. S.N. Singh, "Location of FACTS devices for enhancing power systemssecurity", IEEE power engineering conference on large engineeringsystems, July, 2001

25. F. Qian, G. Tang, and Z. He, "Optimal location and capability ofFACTS devices in a power system by means of sensitivity analysis andEEAC", 3rd International conference on electric utility Deregulation andRestructuring and Power Technologies, DRPT2008, Nanjing China, April, 2008.

26. F.A. El-Sheikhi, Y.M. Saad, S.O. Osman, K.M. El-Arroudi, "Voltage stability assessment using modal analysis of power systems includingFlexible AC Transmision System (FACTS)", IEEE Power EngineeringConference on Large Engineering Systems, May, 2003.

27. I.J.Nagrath and D P Kothari, "Modern Power System Analysis" a book by Tata McGraw Hill, New Delhi.

28. K. Ravi M. Rajaram J. Belwin, "Edward Hybrid Particle Swarm Optimization Technique For Optimal Location Of FACTS Devices Using Optimal Power Flow",2011.

29. M. Saravanan, S. Mary Raja Slochanal, “ Application of PSO for Optimal Location of FACTS considering system loadabilityand cost of installation", The 7th International Power Engineering Conference, IEEE,IPEC 2005.

30. H.R.Baghaee, M.Jannati, B.Vahidi, "Improvement of Voltage Stability and Reduce Power System Losses by optimal GAbased Allocation of Multi-type FACTS Devices", OPTIM International Conference, 2008.

31. JigarS.Sarda, VibhaN.Parmar, DhavalG.Patel,LalitK.Patel, "Genetic Algorithm Approach For Optimal Location Of Facts Devices To Improve System Loadability And Minimization Of Losses", International Journal Of Advanced Research In Electrical, Electronics And Instrumentation Engineering,Vol.1, Issue 3, Sept 2012

32. V. Vahidinasab and A. Mosallanejad A. Kazemi, "Study of STATCOM and UPFC Controllers for Voltage Stability Evaluated by Saddle-Node Bifurcation Analysis," in First International Power and Energy Conference PEC, Putrajaya, Malaysia., November 28-29, 2006, pp. 191-195.

33. R. M. Mathur and R. S. Basati, "Thyristor- Based FACTS Controllers for Electrical Transmission Systems," in IEEE Press Series in Power Engineering, 2002.

34. S. S. Rangarajan, M. Ambili, P. Sujyothiand V. G. Nithya S. Sreejith, "Enhancing The Power Transfer Capability In A Power System Network Using Series Connected Facts Devices For Increased Renewable Penetration," in International Conference on Advances in Electrical Engineering (ICAEE), Vellore, Jan. 2014, pp. $1-6$.

35. T. Nguyen and C.T. Vu, "Complex-Variable Newton-Raphson Load- Flow Analysis with FACTS Devices," in IEEE Transmission and Distribution Conference andExhibition, 2006, pp. $183-190$.

36. P. Simon and M. P. Selvan S.SreejithSishaj, "Investigations on Power Flow Solutions Using Interline Power Flow Controller (IPFC)," in Chennai and Dr.MGR University Second International Conference on Sustainable Energy and Intelligent System (SEISCON 2011), 2011.
37. T. Lie and D.M. Vilathgamuwa J. ChenTjing, "Basic Control of Interline Power Flow Controller," IEEE Power EngineeringSociety Winter Meeting, vol. 2, pp. 521 - 525, 2002.

38. L. Gyugyi and N. G. Hingorani, "Understanding FACTS: Concepts and Technology of Flexible AC Transmission Systems," in IEEE press New York, 2000

39. R. M Piedra and A. Frish, "Digital Signal Processing Comes of Age," IEEE Spectrum, Vol. 33, No. 5, May 1996.

40. Steinmetz, C.P., "Power Control and Stability of Electric Generating Stations," AIEE Trans., Vol. XXXIX, no.2, pp.1215-1287, July 1920

41. Wikins, R., "Practical Aspects of System Stability," IEEE Trans., pp 41-50, 1926

42. P. K. Kundur, "Power System Stability and Control, McGraw-Hill, Inc., New York, 1994.

43. Ranjit Kumar Bindal, "A Review of Benefits of FACTS Devices in Power System", International Journal of Engineering and Advanced Technology (IJEAT) ISSN: 2249 - 8958, Volume-3, Issue-4, April 2014. pp. -105-108.

44. Alok Kumar Mohanty, Amar Kumar Barik, "Power system stability improvement using FACTS Devices", International Journal of Modern Engineering Research (IJMER) Vol.1, Issue.2, pp-666-672 ISSN: 2249-6645.pp.-666-672

45. Narain G, Hingorani, Laszlo Gyugyi "Understanding FACTS: Concepts and Technology of FACTS", IEEE Power Engineering Society.

46. John J. Grainger \& William D. Stevenson, "Power System Analysis", McGraw-Hill

47. J. Machowski, J. W. Bialek, and J. R. Bumby, Power system dynamics: stability and control. Chichester: Wiley, 2008

48. Klein, M., Rogers G.J., Moorty S., and Kundur, P., "Analytical investigation of factors influencing power system stabilizers performance", IEEE Transactions on Energy Conversion, Volume: 7 Issue: 3, Page(s): 382 -390, Sept. 1992.

49. Y. Zou, M. H. Yin, and H. D. Chiang. 2003. Theoretical foundation of the controlling UEP method for direct transient-stability analysis of network preserving power system models. IEEE Trans. Circuits Syst. 50(10): 1324-1336.

50. T. Van Cutsem and C. Vournas. 1998. Voltage Stability of Electric Power System. Norwell, MA: Kluwer.

51. D. J. Hill. 1993. Non linear dynamic load models with recovery for voltage stability studies. IEEE Trans. Power System. 8: 166-176.

52. T. Van Cutsem and R. Mailhot. 1997. Validation of a fast voltage stability analysis method on the Hydro- Quebee System. IEEE Trans. Power System. 12: 282- 292

53. J. D. Ainsworth, A. Gavrilovic and H. L. Thanawala. 1980. Static and synchronous compensators for HVDC transmission convertors connected to weak AC system. 28th Session CIGRE, paper 31-01

54. CIGRE working Group 14.05 Report, Guide for planning DC Links Terminating at AC systems Location Having Low Short-Circuit Capacities Part1: AC/DC Interation Phenomena, CIGRE Guide No.95. 1992

55. 1997. CIGRE Working Group 14.05 Report, Interaction between HVDC convertors and nearby synchronous machine. CIGRE Brochure 119, Oct.

56. Yu YN and Moussa HAM, "Optimal stabilization of a multi-machine system," IEEE Transactions on Power Apparatus and Systems, vol. 91, no. 3, pp. 1174-1182, 1972. Fig.7. a) TCVR base on Tap Changing b) TCVR base on Voltage Injection IJSER International Journal of Scientific \& Engineering Research, Volume 7, Issue 4 April-2016 977 ISSN 2229-5518 IJSER @ 2016 http://www.ijser.org

57. V. Samarasinghe and N. Pahalawaththa, "Damping of Multimodal Oscillations in Power Systems Using Variable Structure Control Techniques", IEEE Proc. Genet. Transm. Distrib. Vol. 144, No. 3, pp 323-331, Jan. 1997.

58. N. S. D. Arrifano, V. A. Oliveira, R. A. Ramos, "Design and Application of Fuzzy PSS for Power Systems Subject to Random Abrupt Variations of the Load", Proceeding of the American Control Conference Boston, Massachusetts June 30 - July 2, 2004

59. G. ShahgholianGhfarokhi, M. Arezoomand, H. Mahmoodian, "Analysis and Simulation of the SingleMachine Infinite-Bus with Power System Stabilizer and Parameters Variation Effects", IEEE, International Conference on Intelligent and Advanced Systems, pp 167- 171, 2007. 
60. D. K. Sambariya, R. Gupta, A. K. Sharma, "Fuzzy Applications to Single Machine Power System Stabilizers", Journal of Theoretical and Applied Information Technology (JATIT), pp. 317-324, 2009.

61. Muawia Abdel KafiMagzoub, Dr. Magdi S. Mahmoud, "Power System Stabilizer (PSS) for Single Machine Connected to Infinite Bus (SMIB) Based on Optimal Control (OP) Techniques", January 2010.

62. V. Ravi, Dr. K. Duraiswamy, "Effective Optimization Technique for Power System Stabilization using Artificial Bee Colony", International Conference on Computer Communication and Informatics (ICCCI), pp. 1-6, January 2012.

63. Vijay. M, Selvakumari S., "Design of Power System Stabilizer to Improve Small Signal Stability," International Journal of Communications and Engineering, Volume 04, No. 4, Issue: 04 March 2012.

64. M. Suguna, "Damping of Low- frequency Oscillations Using Swarm Optimized Controller for SMIB System", International Journal of Engineering and Innovative Technology (IJEIT), Volume 1, Issue 4, April 2012.

65. M. A. Mahmud, H. R. Pota, M.J. Hossain, "Full-order nonlinear observer-based excitation controller design for interconnected power systems via exact linearization approach", ELSEVIER, Volume 41, Issue 1, Pages 54-62, October 2012.

66. D. K. Sambariya, Rajendra Prasad, "Differentiation method based Stable Reduced Model of Single Machine Infinite Bus System with Power System Stabilizer", International Journal of Applied Engineering Research, ISSN 0973-4562, Vol. 7, No. 11, November 2012.

67. G. JeelaniBasha ,N. Narasimhulu, P. Malleswara Reddy, "Improvement of Small Signal Stability of a Single Machine Infinite Bus Using SSSC Equipped With A Hybrid Fuzzy Logic Controller",IJAREEIE, ISSN 2278 - 8875 Vol. 3, Issue 2, February 2014.pp.-7090-7099.

68. E.Kirankumar, Prof. V. C. Veerareddy, "A Novel Hybrid Approach for Stability Analysis of SMIB using GA and PSO", IJAEMS, ISSN: 2454-1311 Vol-2, Issue-4, April- 2016, pp.102-107.

69. A. Sode-Yome, N. Mithulananthan, Kwang Y. Lee, "A Comprehensive Comparison of FACTS Devices for Enhancing Static Voltage Stability" 1- 4244-1298-6/07, 2007, IEEE.

70. MehrdadAhmadiKamarposhti, MostafaAlinezhad, Hamid Lesani, NematTalebi, "Comparison of SVC, STATCOM, TCSC, and UPFC Controllers for Static Voltage Stability Evaluated by Continuation Power Flow Method" 978-1-4244-2895-3/2008 IEEE Electrical Power \& Energy Conference.

71. Ch. Rambabu, Dr. Y. P. Obulesu, Dr. Ch. Saibabu, "Improvement of Voltage Profile and Reduce Power System Losses by using Multi Type Facts Devices" International Journal of Computer Applications (0975 - 8887), Volume 13- No.2, January 201. 